\title{
Naturopathic medicine: Nine parts negative, one part
}

\section{positive [version 1; peer review: 2 approved with reservations]}

\author{
Norman Temple \\ Centre for Science, Athabasca University, Alberta, T9S 3A3, Canada
}

\author{
V1 First published: 25 Jun 2015, 4:169 \\ https://doi.org/10.12688/f1000research.6707.1 \\ Latest published: 25 Jun 2015, 4:169 \\ https://doi.org/10.12688/f1000research.6707.1
}

\section{Abstract}

Naturopathic medicine, also known as naturopathy, is a type of complementary and alternative medicine. It appeals to many people, especially those who desire a "holistic" approach to both prevention and treatment. While there is much variation in the types of treatment used by different naturopaths, commonly used ones include acupuncture, herbalism, and homeopathy. These types of treatment often lack sound supporting evidence of efficacy. But at the same time naturopaths are often hostile to conventional drugs, even those that are of proven effectiveness and pose little risk of harmful side effects. Many naturopaths employ treatments, such as diet, herbs, fasting, and colonic irrigation that are claimed to "detoxify" the body and thereby lead to improved health. There is a complete absence of supporting evidence for this type of therapy. Some aspects of the theories and practices employed by naturopaths are well supported by the evidence. In particular, the emphasis that naturopaths place on leading a healthy lifestyle so as to prevent disease is entirely consistent with modern concepts in this area. Overall, the positive aspects of naturopathy are greatly outweighed by the negative aspects.

\section{Keywords}

Alternative medicine, Complementary and alternative medicine, Naturopathy

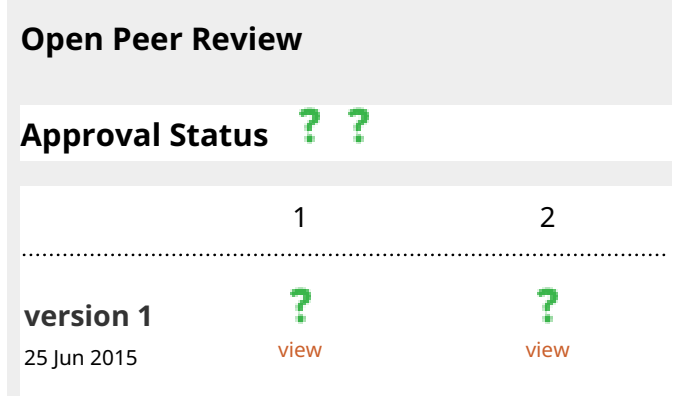

1. Jonathan L. Wardle, University of

Technology Sydney, Ultimo, Australia

2. Charles R. Elder, Kaiser Permanente

Northwest, Portland, USA

Any reports and responses or comments on the article can be found at the end of the article.

Corresponding author: Norman Temple (normant@athabascau.ca)

Competing interests: The author declared no competing interests.

Grant information: The author(s) declared that no grants were involved in supporting this work.

Copyright: (C) 2015 Temple N. This is an open access article distributed under the terms of the Creative Commons Attribution License, which permits unrestricted use, distribution, and reproduction in any medium, provided the original work is properly cited. Data associated with the article are available under the terms of the Creative Commons Zero "No rights reserved" data waiver (CC0 1.0 Public domain dedication).

How to cite this article: Temple N. Naturopathic medicine: Nine parts negative, one part positive [version 1; peer review: 2 approved with reservations] F1000Research 2015, 4:169 https://doi.org/10.12688/f1000research.6707.1

First published: 25 Jun 2015, 4:169 https://doi.org/10.12688/f1000research.6707.1 


\section{Introduction}

Naturopathic medicine - naturopathy - is a popular type of complementary and alternative medicine (CAM) that has steadily evolved over the last 100 years $^{1}$. Naturopaths believe that the human body strives toward health and is its own best healer. Naturopaths claim to treat the whole person using natural therapeutics and cures ${ }^{2}$. However many aspects of naturopathy suffer from a serious lack of solid supporting evidence.

Patients choose to visit naturopaths for a variety of reasons. The most important of these is an attraction to the overall philosophy of naturopathy, including the desire for a more "natural" and "holistic" approach that (supposedly) addresses the root of the problem ${ }^{2}$. Other reasons include general dissatisfaction with the care provided by conventional health-care providers, wanting more time and attention, and having had a previous positive experience with a naturopath. The patients who most often visit a naturopath are white, middle-aged, female, and have a chronic condition ${ }^{3}$.

Naturopathic physicians (NDs) are trained as primary-care physicians in four-year, accredited doctoral-level naturopathic medical schools. There are several such schools in the USA and Canada ${ }^{4}$. The legal status of naturopaths varies between states and provinces. Some jurisdictions permit registered naturopaths to carry out minor surgery, write prescriptions for at least some drugs, give vaccinations, and carry out spinal manipulations.

\section{Guiding principles of naturopathy}

Naturopathy embraces the concept of prevention which is best accomplished by educating their patients to lead a healthy lifestyle. In that respect naturopathy resembles health promotion. A generally healthy lifestyle is now recognized as the ideal way to prevent many diseases including coronary heart disease, type 2 diabetes, and hypertension ${ }^{5}$.

Naturopaths take a holistic approach to treatment and thereby aim to treat the whole person ${ }^{4,6}$. They see this approach as being superior to that of conventional medicine which takes a mechanistic view of disease (reductionism) and then focuses on symptoms. With some diseases a whole-person (holistic) approach can make good sense. For example, coronary disease is the result of a generally unhealthy lifestyle that causes dysfunction in several body systems. A generally healthy lifestyle is effective for not only the prevention of coronary heart disease but also as a treatment ${ }^{5}$. This is also the case with type 2 diabetes and hypertension ${ }^{5}$. A holistic approach may also be of value in patients with cancer as they need nutritional support to help the body recover as well as social and emotional support. A holistic approach to coronary disease and cancer is hardly controversial and most cardiologists and oncologists would probably support this, provided, of course, that effective treatments that target the specific disorder are also employed.

An altogether different story presents itself with other disorders. With arthritis and depression, for example, there can be a specific dysfunction in a single body system. Conventional medicine has treatments of proven effectiveness that target the problem. In these cases treating the whole body will likely lead to poorer outcomes.
One of the core principles of naturopathic medicine is to use treatments that minimize risk to the patient. Of course, conventional physicians also claim to follow this principle. However, there is no doubt that on many occasions physicians have indeed given inappropriate treatments causing harm. The obvious solution to this is to improve the quality of treatment given by conventional physicians. But we must recognize that harmful side effects are often the price patients must pay in order to receive benefit. For example, cancer therapy often involves the use of drugs, radiation, and/or surgery which while helpful in the treatment of the disease can have harmful side effects.

Many naturopaths believe the suppression of symptoms should be avoided because such an action interferes with the healing process ${ }^{6}$. This leads to a situation where naturopaths may refuse to give analgesic medications to a patient with arthritis or anti-depressants to one with depression, thereby depriving the patient of potentially helpful treatments ${ }^{6}$. Moreover, there is no evidence that these drugs prevent the healing of the joints in arthritic patients or impede the brain from normalizing the neurochemical imbalances causing some forms of depression.

\section{The practice of naturopathy}

Practitioners of CAM use a wide range of therapies, several of which have been adopted by naturopathy. These include herbalism, homeopathy, acupuncture, hydrotherapy, physical therapy, spinal manipulation, lifestyle counseling, nutrition (including the use of vitamin and mineral supplements), and psychological counseling. Some of these treatments do not stand up to close scrutiny. There is much variation in the eclectic choice of therapies used by individual naturopaths. As part of their practice naturopaths carry out patient assessment and diagnosis using standard approaches including physical examination, lab tests, and clinical assessment.

As noted above, the logic of naturopathy dictates that practitioners should whenever possible avoid giving pain killers to a patient with arthritis or anti-depressants to one with depression. But most naturopaths strongly support the use of herbal medicine ${ }^{3,6}$. For example, naturopaths sometimes recommend the use of herbal medicines for treating cervical dysplasia ${ }^{6}$, despite a lack of supporting evidence. By contrast, the standard medical procedure involves minor surgery, which is safe and effective. Similarly, mistletoe may be recommended by naturopaths for the treatment of hypertension ${ }^{6}$, even though it has not been properly tested in clinical trials and is toxic. Yet, drugs are often avoided despite being reasonably safe and effective.

Herbal medicines are merely plant extracts that contain chemicals with drug-like action. Indeed, many of today's drugs started life in previous centuries as herbal treatments. The attitude of naturopaths towards herbal medicines and drugs is therefore irrational.

Similar irrationality is seen with homeopathy, a type of CAM that is highly controversial and far from being proven as effective ${ }^{7,8}$. Nevertheless, the therapy is an integral part of the practice of many naturopaths $s^{1,3,9}$. Acupuncture is another modality often used by naturopaths as a treatment for many disorders ${ }^{3,9}$ but its proven value is very limited beyond the control of pain ${ }^{10}$. 
One of the fundamental principles of naturopathy since its birth a century ago is the general claim that much sickness is caused by an accumulation of toxins in the body ${ }^{1}$. Accordingly, an important therapy in curing disease is the application of treatments that help eliminate these toxins. This concept - detoxification - is still the basis for various naturopathic therapies today ${ }^{6}$. Fasting is often employed in the belief that it induces detoxification. A variation of this approach is autotoxicity where the focus is toxins in the colon. This is commonly treated by colonic irrigation, a procedure that is potentially harmful as it can hyper-extend the colon ${ }^{11,12}$.

There is no credible evidence that detoxification treatments, such as dietary changes, consumption of herbs and supplements, fasting, or colonic irrigation, can remove toxins from the body or lead to improved health. These beliefs seem to be based on little more than speculation. Nevertheless, a survey of naturopaths in the USA found that $92 \%$ reported using detoxification therapies ${ }^{13}$. Similarly, a survey of naturopaths in Canada found more than half were using fasting as a treatment for various conditions ${ }^{9}$.

Hydrotherapy is another healing modality that naturopathy inherited from previous times. This treatment was very popular in central Europe where many people would go to a spa and sit in a pool containing spring water that was credited with healing properties. Indeed, this therapy is still popular in parts of Europe. The therapy was imported into the USA. Hydrotherapy is advocated by many naturopaths, often with the claim that it aids in detoxification and helps strengthen immune function ${ }^{1}$. Certainly, spending time in a sauna, hot tub, spa, or sanatorium is relaxing, but there is little evidence that hydrotherapy has any more direct therapeutic value. Interestingly, a recent observational study carried out on men in Finland reported a protective association between use of a sauna and reduced risk of cardiovascular disease and of all-cause mortality ${ }^{14}$.

Iridology is a technique where practitioners examine a patient's eye and then make a diagnosis based on changes in the iris. The technique rests on the claim that many disorders can be diagnosed using the technique but it has no scientific basis ${ }^{15}$. Nevertheless, $23 \%$ of naturopaths in Canada reported using iridology in their practice 9

\section{Positive aspects of naturopathic medicine}

Some aspects of naturopathic medicine compare favorably with conventional medicine. As was stated earlier, naturopathic medicine places a strong emphasis on avoiding treatments that pose a risk. Unfortunately, what this can often mean is that patients are denied treatments that are effective while posing an acceptably low risk of harm. But conventional physicians often go too far in the opposite direction. In particular, there have been many stories over the past several decades of medications being prescribed that cause significant harm. A recent example is OxyContin, an opioid widely used for the relief of pain. The over-prescribing of this medication by physicians has led to an epidemic of addiction and resulted in many deaths ${ }^{16,17}$.

Naturopaths place a strong emphasis on preventive medicine by means of encouraging their patients to live a healthy lifestyle. Moreover, they have been critical of conventional medicine for failing to be active in this area. There may have been much truth to this in the past but over the last several decades conventional medicine has given much attention to this crucial area. This includes strong support for health promotion and various efforts to prevent disease at the population level. In addition, conventional physicians routinely screen middle-aged patients for such conditions as diabetes, hypertension, and high blood cholesterol. Interventions are then made where appropriate so as to prevent disease. However, what conventional physicians do, more often than not, is to write a prescription rather than encourage their patients to follow a healthy lifestyle. For example, one study on obesity showed that less than one third of Canadian physicians advised their overweight patients to lose weight ${ }^{18}$.

The obvious explanation for why conventional physicians routinely ignore lifestyle when treating their patients is lack of time. Counseling patients on making lifestyle changes takes far more time than writing a prescription for drugs that treat hypertension or high blood cholesterol. In a system where physicians generally spend no more than 10 or 15 minutes on each consultation, it is simply not possible to make a serious effort to assess a patient's lifestyle and then deliver appropriate counseling. Naturopaths, by contrast, spend much more time with their patients; a typical first office visit to a naturopath takes one hour ${ }^{6}$ while an average visit takes around 42 minutes ${ }^{3}$.

\section{Conclusions}

A challenge in analyzing the practice of naturopathy and of critically evaluating its advantages and disadvantages is that relatively few research studies have been carried out. There is an urgent need for more research.

Naturopathic medicine offers an approach to health that appeals to many people: it is considered to be "holistic", based on prevention, promises treatments that "detoxify" the body, and avoids the potential hazards often seen with conventional medicine. However, naturopathic medicine has serious negative features including the use of treatments that have little or no supporting evidence, such as homeopathy and treatments intended to bring about detoxification. Similarly, naturopaths use treatments where the supporting evidence is weak, such as many uses of acupuncture and herbalism. Naturopaths frequently fail to prescribe drugs where the benefit strongly outweighs the risk.

Naturopathic medicine does have some positive features, especially its strong emphasis on encouraging patients to prevent disease by living a healthy lifestyle. Conventional physicians, by contrast, are much less likely to dispense lifestyle advice, mainly due to lack of time. However, this is a rather weak advantage of naturopathy as the benefits of a healthy lifestyle are already well known by the majority of the population, especially by people who are most likely to visit a naturopath.

Overall, the positive aspects of naturopathy are greatly outweighed by the negative aspects.

Competing interests

The author declared no competing interests.

Grant information

No funding was involved in supporting this work. 
1. Pizzorno JE, Snider P, Micozzi MS: Nature Cure, Naturopathy and Natura Medicine. In: Micozzi M, ed. Fundamentals of complementary and alternative medicine. St Louis, MO: Elsevier (Saunders). 2015; 347-65.

Reference Source

2. Elder CR: Integrating naturopathy: can we move forward? Perm J. 2013; 17(4): 80-3.

PubMed Abstract | Publisher Full Text | Free Full Text

3. Boon HS, Cherkin DC, Erro J, et al.: Practice patterns of naturopathic physicians: results from a random survey of licensed practitioners in two US States. BMC Complement Altern Med. 2004; 4: 14.

PubMed Abstract | Publisher Full Text | Free Full Text

4. Fleming SA, Gutknecht NC: Naturopathy and the primary care practice. Prim Care. 2010; 37(1): 119-36.

PubMed Abstract | Publisher Full Text | Free Full Text

5. Temple NJ, Wilson T, Jacobs DR Jr: Nutritional health: strategies for disease prevention. 3rd ed. New York: Humana Press, 2012. Publisher Full Text

6. Pizzorno JE, Snider P: Contemporary naturopathic medicine. In: Micozzi M, ed Fundamentals of complementary and alternative medicine. St Louis, MO: Elsevier (Saunders). 2015; 366-86.

Reference Source

7. Bewley S, Ross N, Braillon A, et al:: Clothing naked quackery and legitimising pseudoscience. BMJ. 2011; 343: d5960.

PubMed Abstract | Publisher Full Text

8. Fisher PA: What about the evidence base for homeopathy? BMJ. 2011; 343 : d6689.

PubMed Abstract | Publisher Full Text

9. Verhoef MJ, Boon HS, Mutasingwa DR: The scope of naturopathic medicine in Canada: an emerging profession. Soc Sci Med. 2006; 63(2): 409-17. PubMed Abstract | Publisher Full Text
10. Ernst E, Pittler MH, Wider B, et al.: The desktop guide to complementary and alternative medicine: an evidence-based approach. Toronto: Mosby. 2006. Reference Source

11. Acosta RD, Cash BD: Clinical effects of colonic cleansing for general health promotion: a systematic review. Am J Gastroenterol. 2009; 104(11): 2830-6, quiz 2837. PubMed Abstract | Publisher Full Text

12. Mishori R, Otubu A, Jones AA: The dangers of colon cleansing. J Fam Pract. 2011; 60(8): 454-7. PubMed Abstract

13. Allen J, Montalto M, Lovejoy $\mathrm{J}$, et al.: Detoxification in naturopathic medicine: a survey. J Altern Complement Med. 2011; 17(12): 1175-80. PubMed Abstract | Publisher Full Text | Free Full Text

14. Laukkanen $\mathrm{T}$, Khan $\mathrm{H}$, Zaccardi $\mathrm{F}$, et al:: Association between sauna bathing and fatal cardiovascular and all-cause mortality events. JAMA Intern Med. 2015; 175(4): 542-8

PubMed Abstract | Publisher Full Text

15. Knipschild $P$ : Looking for gall bladder disease in the patient's iris. BMJ. 1988; 297(6663): 1578-81. PubMed Abstract | Publisher Full Text | Free Full Text

16. Webster PC: Medically induced opioid addiction reaching alarming levels. CMAJ. 2012; 184(3): 285-6.

PubMed Abstract | Publisher Full Text | Free Full Text

17. Dhalla IA, Mamdani MM, Sivilotti ML, et al:: Prescribing of opioid analgesics and related mortality before and after the introduction of long-acting oxycodone. CMAJ. 2009; 181(12): 891-6.

PubMed Abstract | Publisher Full Text | Free Full Text

18. Kirk SF, Tytus R, Tsuyuki RT, et al:: Weight management experiences of overweight and obese Canadian adults: findings from a national survey. Chronic Dis Inj Can. 2012; 32(2): 63-9.

PubMed Abstract 


\section{Open Peer Review}

\section{Current Peer Review Status: ? ?}

\section{Version 1}

Reviewer Report 29 December 2015

https://doi.org/10.5256/f1000research.7204.r11703

(C) 2015 Elder C. This is an open access peer review report distributed under the terms of the Creative Commons Attribution License, which permits unrestricted use, distribution, and reproduction in any medium, provided the original work is properly cited.

\section{Charles R. Elder \\ Center for Health Research, Kaiser Permanente Northwest, Portland, OR, USA}

This is a timely topic and the report is well organized however I have a number of major concerns.

First, the tone of the report is not well balanced, and provides harsh criticism of naturopathy but with insufficient exploration of potential benefits. Secondly, there are numerous criticisms of naturopathy which are offered as statements of fact that in reality are unsubstantiated, or incorrect. For example, the author states:

"With arthritis and depression, for example, there can be a specific dysfunction in a single body system. Conventional medicine has treatments of proven effectiveness that target the problem. In these cases treating the whole body will likely lead to poorer outcomes."

In reality, these two conditions are often recalcitrant to conventional therapies, and may be appropriate areas for including complementary therapies. As another example, the author states:

"There is no credible evidence that detoxification treatments, such as dietary changes, consumption of herbs and supplements, fasting, or colonic irrigation, can remove toxins from the body or lead to improved health. These beliefs seem to be based on little more than speculation."

Yet there is evidence in the biomedical literature of reductions in inflammatory markers associated w/ fasting, and Ayurvedic medicine provides a long tradition, therapeutic rationale, and vast body of anecdotal evidence supporting the use of such detoxification procedures.

Finally, it is unclear what the real purpose of the article might be. Is this an attempt to encourage dialogue between naturopaths and conventional clinicians? Is the purpose to educate conventional clinicians about the role, and limits, or naturopathy? Is the purpose to simply criticize naturopathy?

What could be a constructive message, or contribution, for the essay? I think the project has 
excellent potential once this issue is clarified.

Competing Interests: No competing interests were disclosed.

I confirm that I have read this submission and believe that I have an appropriate level of expertise to confirm that it is of an acceptable scientific standard, however I have significant reservations, as outlined above.

Reviewer Report 23 September 2015

https://doi.org/10.5256/f1000research.7204.r10440

(C) 2015 Wardle J. This is an open access peer review report distributed under the terms of the Creative Commons Attribution License, which permits unrestricted use, distribution, and reproduction in any medium, provided the original work is properly cited.

Jonathan L. Wardle

Australian Research Centre in Complementary and Integrative Medicine (ARCCIM), Faculty of Health, University of Technology Sydney, Ultimo, NSW, Australia

Initially it is only right that I completely disclose my potential conflict of interest up front. In addition to my qualifications in public health and law I am also qualified as a naturopath. This would suggest that I - automatically - would disagree with the premise of the article. However, I will review the article below on its merits alone. This article is also clearly labelled as a commentary, so my criticism will also bear this in mind. This relates to the author's opinion, I will only highlight where I think this opinion is not necessarily argued well or on fact.

\section{Title and abstract:}

1. I would suggest that the title, whilst certainly poetic, does not really reflect the content of the article. I do not think the author has offered 'nine negatives' to each 'positive' (in fact, there appears to be nearly as much word count supporting naturopathy as there is arguing against it). I think that as it stands the article's title reflects a strength of argument that isn't there. I think that there are less 'quantitatively driven' titles the author could choose, or the author could modify content to address the current mismatch between title and content. There is far more positive discussion of aspects of naturopathic care than the title would suggest.

2. The abstract tends to describe naturopaths as a homogenous group, and I would suggest that qualifiers such as 'many naturopaths are hostile' or 'a proportion of naturopaths are hostile' would be more accurate than blanket statements. It is undeniably true that these opinions exist, but the homogeneity of opinion certainly does not.

\section{Article content:}

I give specific comments below, in the order that they appear in text:

1. In the introduction the author does not appear to define naturopathy correctly. It is a 
principles-based system of medicine (just as Chinese medicine and Ayurveda are). Detoxification is not one of these principles. The principles - adopted by the World Naturopathic Foundation and recognized by the World Health Organization - are summarized here - http://aanmc.org/naturopathic/6principles/. Given that the author has used 'guiding principles' as a sub-heading this omission appears particularly noticeable.

2. I think the author over-simplifies clinical care when he suggests that it is a different story altogether' in conditions like arthritis and depression. Holistic management of these conditions is considered important even in conventional care (e.g. depression associated with arthritis, functionality, and fatigue in rheumatoid arthritis). Moreover, he author makes the critically incorrect assumption that naturopaths ignore symptomatic treatment, with a whole body approach 'leading to worse outcomes'. Like conventional medicine, naturopathic medicine has a spectrum of healing approaches individualized to patient need. A cursory glance of the depression and arthritis chapters of naturopathic texts would have confirmed this (such as Sarris J; Wardle J (eds) (2014) Clinical Naturopathy: An EvidenceBased Guide To Practice, 2 2 nd edition. Churchill Livingstone: Sydney ISBN: 978-0-7295-4173-2 - used as a core text in over a dozen countries including the author's own). Moreover, I find the choice of depression particularly interesting, given the high level of evidence of a specific naturopathic treatment in that condition (St John's Wort), which is superior to many conventional medicines.

3. The author appears to assume that naturopathic and conventional medicine do not interact or integrate, and discussed them as completely separate entities. One of the glaring examples of this is the discussion of cancer treatments - specifically the discussion of the 'harmful effects price pay-off' of cancer treatment. However, part of the core focus of modern naturopathic oncology treatment is to integrate with conventional oncology and to support this treatment through positive interactions (which increase the effect of chemotherapeutics), reduction of side effects from conventional treatment and to improve quality of life throughout. This is the treatment taught in naturopathic schools (and in Janet Schloss' cancer chapter in the aforementioned Sarris and Wardle text) and practiced (see Dugald Seely's research papers in PubMed, or view the work at the Ottawa Integrative Cancer Centre - and external teaching clinic of the Canadian College of Naturopathic Medicine).

4. The author overplays naturopathic resistance to conventional medicine. The approach taken by naturopaths is classed as the Therapeutic Order. Suppressing Pathology is not discouraged completely, simply only encouraged to be used sparingly and not as first-line treatment. A full explanation can be found here:

https://www.researchgate.net/publication/43328689_A_hierarchy_of_healing_the_therapeutic_order or in the relevant clinical chapters mentioned previously.

5. It is probably worthwhile, in the introduction to the section on practice, to highlight the fact that naturopaths are defined by their philosophy, and not by their tools of trade.

6. The logic used to suggest that naturopaths would 'whenever possible' not give pain-killers or anti-depressants. Many of the herbal or other therapeutic agents have very similar profiles (e.g. herbal analgesics or capsacain, St John's Wort is essentially a SSRI). In severe depression and other mental health disorders naturopathic texts discuss - at length - co- 
management with pharmaceuticals. In some US states naturopaths have prescribing rights and prescribe these treatments (in fact, in Washington about $12 \%$ of naturopaths administer vaccines).

7. In the entire practice section the author appears to cherry-pick treatments - including some (such as iridology) that are considered fringe even by naturopaths. The author uses the example of mistletoe in hypertension, which misses the point not only because it is rarely used but also because whole-system naturopathic care does have evidence for improvement in hypertension (e.g. see Bradley R, Kozura E, Kaltunas J, Oberg EB, Probstfield J, et al. (2011) Observed Changes in Risk during Naturopathic Treatment of Hypertension. Evid Based Complement Alternat Med 2011: 826751 and Seely, Dugald, et al. "Naturopathic medicine for the prevention of cardiovascular disease: a randomized clinical trial." Canadian Medical Association Journal 185.9 (2013): E409-E416) - with treatments not including mistletoe.

8. Herbal medicines are far more complex than the author suggests (e.g. see the importance of 'whole herb' hyperforin, hypericin etc reactions in St John's Wort - or the work of the World Health Organization on collection, harvesting and manufacturing herbal medicines) and therefore is not irrational. It is difficult to see, without any compelling argument of any kind, how the author can suggest naturopaths using herbal medicines simply because they are chemical as being irrational either.

9. The author conflates fasting (of which there is much evidence - especially in chronic conditions such as RA) with detoxification, overstates the importance of detoxification (probably through an overly simplified interpretation of toxic load theory - which is more to do with a mnemonic for reducing the impact of metabolic wastes). 'Detoxification therapies' in naturopathic care can include anything from undoubtedly beneficial therapies such as encouraging more water intake, more regular bowel motions, increased fibre to less likely to be beneficial treatments such as foot spas. Given this breadth it is not surprising that $92 \%$ stated using them.

10. The author is also confused on hydrotherapy - confusing balneotherapy with hydrotherapy at one stage. Hydrotherapy is the therapeutic application of pressure or heat via water - ice compresses are probably the most commonly known of these, but there are numerous other treatments. Leon Chaitow's text 'Naturopathic Physical Medicine' published by Elsevier has a good chapter authored by Eric Blake on this topic should the author require more detail. The author highlights one study on sauna therapy - but there are many more he could find if he searched PubMed.

11. The author states that the beneficial aspects of naturopathic care can easily be resolved by giving conventional physicians more time. I think this is an overly simplistic interpretation. There are socio-cultural and philosophical reasons for these differences, suggesting they are merely time-based is disingenuous, and not borne out from the data. Observational studies of naturopathic practice have found that health promotion counseling on diet, physical activity, and stress management is incorporated into almost every clinical encounter (80\%-100\%) and is reinforced over successive patient visits. This finding diverges substantially from the low rates of health promotion in conventional care $(<35 \%-40 \%)$. These REFS can be found in the following article - Wardle J; Oberg E (2011) “The intersecting 
paradigms of naturopathic medicine and public health: opportunities for naturopathic medicine" Journal of Alternative and Complementary Medicine 17(11); pp1079-84

\section{Conclusions:}

1. I feel the statement that naturopaths use treatments where the evidence is weak is too general and too directive. The same can be said of any profession (there is very little evidence for physiotherapy - see last year's BMJ review - and conventional physicians continue to perform knee arthroscopy more than a decade after it has been unequivocally demonstrated to have little clinical value). I agree that more research is needed, but there is also areas in which naturopathic care has demonstrable value in the evidence base.

2. I feel as though, rather than attempting to discredit an entire profession through a few cherry-picked examples, the author would make a better argument by highlighting some of the issues that may make naturopathic care sub-optimal. I have written many of these myself. The very nature of naturopathic medicine may attract people distrustful of conventional medicine with conflicting scientific and philosophical worldviews (see Heather Boon's work or Amie Steel's work on naturopaths engaging with evidence). The lack of regulation in many jurisdictions means that naturopaths can practice with little or no training. The 'broad church' and inclusive nature of naturopathy may make it easier for fringe therapies to establish. Gort and Coburn suggest that the marginalization of naturopathic medicine itself may encourage it adopt marginal doctrines that bear little philosophical relation to naturopathic practice. However, I feel as though the few cherrypicked and poorly researched topics chosen by the author do little to advance their argument.

I feel as though the author has spoken beyond the data on numerous occasions. However, as a commentary piece this should reflect their views. There are some, I believe, errors of fact that need to be addressed. Overall, most of the problems with content I put down to poor knowledge of the topic. Complementary medicine is a highly politically charged topic that can lead to strong opinions on 'both sides' of the debate. I think that this article needs to be either more measure if it is to keep its current form, or if it is to keep its current tone the arguments need to be made far more compelling. As it stands it is a commentary which clearly highlights one authors view of the topic, but it does not convince a reader that this view is a 'rational' one (to use the author's terms).

Competing Interests: I am trained as a naturopathic practitioner, and this article takes a less than supportive view of this profession.

I confirm that I have read this submission and believe that I have an appropriate level of expertise to confirm that it is of an acceptable scientific standard, however I have significant reservations, as outlined above.

\section{Comments on this article}

Version 1 
Author Response 08 May 2016

Norman Temple, Athabasca University, Alberta, Canada

I thank Drs Elder and Wardle for their comments on my paper. Their comments provide an excellent illustration of the problems associated with making an objective and scientific assessment of complementary and alternative medicine (CAM). I have been following the debate on the value of CAM for 40 years and have seen a great many examples of people arguing with complete conviction that one or other of the theories or modes of treatment advocated by practitioners of CAM is based on solid evidence, when a closer inspection of that evidence reveals it to be deeply flawed.

This problem certainly applies to naturopathy. Indeed, I could have added the words: "the emperor is (almost) naked" to the title of the paper but I had already used that phrase in a previous paper ${ }^{1}$. That paper was on the subject of the marketing of dietary supplements, another area that suffers from mangled scientific evidence.

For reasons of brevity I will be limited in my responses to the two reviewers. Dr Elder argues in support of therapies intended to bring about detoxification. However, a search at Medline reveals an almost total absence of scientific studies on the subject. Dr Elder refers to a "vast body of anecdotal evidence" coming from Ayurvedic medicine that supports the value of detoxification. This type of evidence is frequently employed by those who put their faith in CAM. We often see it with herbal treatments and acupuncture. But, time and time again, such evidence is shown to be worthless when tested by well-designed randomized controlled trials (RCTs).

Dr Elder criticizes my statement that fasting is of no therapeutic value by referring to evidence that fasting brings about reductions in inflammatory markers. There are two problems with this argument. First, we must be very cautious before concluding that a change in the levels of biomarkers equates to an improvement in health. Second, a much more practical way to improve the level of biomarkers for inflammation is to improve the diet. For example, a meta-analysis of RCTs reported that the Mediterranean diet leads to a decrease in various biomarkers of inflammation ${ }^{2}$.

Dr Wardle accuses me of "attempting to discredit an entire profession through a few cherry-picked examples." Those are my sentiments exactly (though in reverse).

In conclusion, I encourage anyone making an assessment of not only naturopathy but also CAM in general to apply a healthy dose of skepticism. That was noticeably absent from the comments by the two reviewers.

1. Temple NJ. The marketing of dietary supplements in North America: The emperor is (almost) naked. J Altern Complement Med. 2010; 16(7): 803-6.

2. SchwingshackI L, Hoffmann G. Mediterranean dietary pattern, inflammation and endothelial function: a systematic review and meta-analysis of intervention trials. Nutr Metab Cardiovasc Dis. 2014; 24(9): 929-39. 
Competing Interests: No competing interests were disclosed.

The benefits of publishing with F1000Research:

- Your article is published within days, with no editorial bias

- You can publish traditional articles, null/negative results, case reports, data notes and more

- The peer review process is transparent and collaborative

- Your article is indexed in PubMed after passing peer review

- Dedicated customer support at every stage

For pre-submission enquiries, contact research@f1000.com 